\title{
The Cultivation of Students' Musical Expressiveness in Piano Performance Teaching
}

\author{
Xiao Han \\ Nanjing Normal University, Nanjing 210023, Jiangsu, China \\ Email: xiaoxiaohanhan223@126.com
}

\begin{abstract}
This article believes that in piano performance teaching in colleges and universities, the significance of cultivating students' musical expressiveness is mainly reflected in three aspects: the future development of students, the development of piano art and the reform of education and teaching. In the specific training path, it is necessary to scientifically grasp the relationship between performance technology and music performance, enhance students' awareness of music analysis, and effectively improve students' theoretical accomplishment and create a display platform to exercise students' performance ability.
\end{abstract}

Keywords: colleges and universities, piano performance teaching, students' musical expressiveness, training

Colleges and universities are important positions for cultivating piano talents, and are of great significance to the inheritance of piano music culture. The artistic value of piano works and the formation of people's aesthetic conception of piano music depend on the performance of the performer. In the current piano performance teaching in colleges and universities, teachers and students pay too much attention to the level of performance technology teaching, which leads to students' lack of in-depth understanding of music performance. Especially in many concerts and music competitions, although students are fully competent in performance skills, there is no real content in the interpretation of the musical image of the work, the expression and expression of musical emotions. As a result, most piano students are completely "art for the sake of technology". How to fundamentally improve the current teaching situation, or to realize the effectiveness of piano performance teaching and reflect the value of teaching practice from the perspective of the cultivation of students' musical expressiveness, is a question worthy of careful consideration. This article attempts to start from this angle and talk about my own understanding combined with teaching practice.

\section{The significance of cultivating students' musical expressiveness in college piano performance teaching}

\subsection{Significance to the future development of students}

The most direct purpose of piano performance teaching in colleges and universities is to cultivate piano art talents, including piano performing talents, education talents, etc. This is of great significance to the prosperity of social music life and the improvement of the country's cultural soft power. As an art form, piano performance ultimately needs to be displayed on the stage, which reflects the performer's personal artistic accomplishment and performance value. In the past two decades, on the one hand, the expansion of college enrollment has provided the majority of piano practitioners with opportunities for "further training". On the other hand, with the development of my country's social economy and the continuous improvement of the people's material and spiritual cultural level, the Demand has also grown steadily year by year. The above two situations are both opportunities and challenges for piano students. This shows that the importance of cultivating students' musical expressiveness in piano teaching is an important motivation for coping with academic competition and competition in the workplace, and it adds gold to the future development of students at a certain level.

\subsection{Significance to the development of piano art}

Counting from the Western Baroque period, piano art has gone through more than 350 years. During this period, many composers and performers have made arduous efforts for the creation of piano music and the development of performance skills. Especially since the 20th century, the music practice activities of piano artists represented by Chinese composers and performers have made significant contributions to the development of world piano art. Regardless of the diachronic or synchronic development of piano art, it is inseparable from the cultivation of piano art talents. For the listeners, the reason why they can appreciate different styles of piano music in their daily life satisfies their own auditory experience and 
aesthetic pursuit, which is also the result of the joint efforts of piano artists. Therefore, in piano performance teaching in colleges and universities, the cultivation of students from the perspective of musical expression plays a decisive role in the development of piano art.

\subsection{Significance to education and teaching reform}

Any kind of subject teaching, including the use of teaching models and teaching methods, is based on the basis of invariance and change. The so-called "unchanged" means that each subject has its own teaching rules and teaching characteristics, which is a relatively fixed part of teaching practice. If it goes beyond the scope of the teaching law, it will inevitably lead to the decline of subject development. The so-called "change" means that with the development of the times and social changes, new teaching concepts, models or methods will be widely used in subject teaching, which can promote subject teaching more effectively. In piano performance teaching, the cultivation of students' expressiveness not only needs to follow the gradual teaching rules, but also needs to pay attention to the use of innovative teaching models and methods. The practical application of these models and methods can reflect the practical significance of education and teaching reform.

\section{The cultivation path of students' musical expressiveness in piano performance teaching in colleges and universities}

\subsection{Scientifically grasp the relationship between performance technique and music performance}

In piano performance, the macroscopic musical performance includes three interrelated aspects. The first is the sound performance, that is, the achievement (notation of musical score) in the original creation is transformed into audible sound through operational practice. The second is content performance. In music, there are two levels of music image and music emotion. Among them, the musical image is the object that the composer wants to express, and it reflects the composer's original creative motivation. Musical emotion is the meaning given to the musical image by the composer. In essence, music is a kind of lyrical art, and this lyrical characteristic is embedded in the musical image through the process of expression. The third is stage performance, that is, the body language shown by the performer when interpreting music on the stage, including body language, facial expressions, and eye expressions. From a specific perspective, although the above three points to different aspects of performance, they are all related to each other. In the current piano teaching, performance technology is admired to the supreme position, largely ignoring the three categories of musical performance and its importance. Therefore, in order to improve students' musical expression, the first problem to be solved is to scientifically grasp the relationship between playing technique and musical performance. The aesthetics of musical performance believes that the internal mechanism and core feature of musical performance lies in the unity of technique and performance. If you fail to clarify and grasp the relationship between the two, blindly show off the technique and ignore the performance of music, it can only be said that the original meaning of music is not shown.

\subsection{Enhance students' awareness of the analysis of musical works}

The concept of modern educational psychology believes that consciousness has two concepts in a broad sense and a narrow sense. The broad sense of consciousness refers to the unity of people's knowledge, affection, and intention, while the narrow sense of consciousness refers to the degree of people's awareness and attention to the outside world and the body. In teaching, students' awareness of active learning and their knowledge of the breadth and depth of subjects can help improve their own learning and practical abilities. In the interpretation of any piano music work, the first thing to do is to analyze the music. This is mainly because the music works contain a certain creative background, musical style, and the creative thinking and techniques of the composer. Through the analysis of musical works, we can not only grasp the characteristics of the style of musical works from the perspective of combining perceptual and rational, but also help students understand the application of performance skills. The lack of current piano students' awareness of analyzing musical works has led to students' lack of awareness of musical performance. Therefore, in the piano performance teaching, teachers should increase the content of music analysis, and help students to grasp the style characteristics, technical significance, and performance content of the works by using the method of combining lectures and demonstrations.

\subsection{Improve the curriculum, and effectively improve students' theoretical accomplishments}

Because piano students put too much experience on piano practice in the process of art study and college entrance examination, the students have a very weak cultural foundation. This is a common phenomenon among piano students in colleges and universities. In terms of subject orientation, the humanities category of piano performance subject 
terminology, even though piano performance is more practical, its practicality is based on theory, so the improvement of students' musical expressiveness cannot rely solely on operational practice., But to attach great importance to theoretical cultivation. In the effective undergraduate yearning or three-year postgraduate teaching period, for the school, the curriculum should be improved reasonably and the content of humanities courses should be increased, such as music aesthetics, music performance psychology, drama performance, music analysis, music history, etc. Curriculum, through the setting of courses in these disciplines, enables students to attach importance to their own theoretical cultivation, thereby improving their own musical expression. For example, through the study of music history, music analysis and other courses, students can understand the creative characteristics of piano composers in different periods and grasp the style of musical works, especially the characteristics of representative piano works of Baroque, classicism, and romanticism. Achieve a full understanding, and effectively apply these theoretical knowledge to music performance through the mastery of these theoretical knowledge.

\subsection{Create a display platform to exercise students' performance ability}

The cultivation of musical expressiveness of piano majors should not only be limited to the classroom, but must gain rich experience and carry out sufficient reflection in the continuous performance practice. Through the accumulation of practice, I found my own shortcomings, and then corrected them in subsequent teaching and performances. At present, the school's investigation of students' professional skills is mostly in the form of teaching report concerts. Fundamentally speaking, this method of investigation has the characteristics of summative evaluation and cannot fully reflect the investigation of students' expressiveness. Therefore, in teaching practice, schools and teachers should seek more opportunities to provide students with a platform for self-expression, directly or indirectly, through different evaluation methods such as self-evaluation and other-evaluation to examine the performance of students. For example, the regular biweekly concerts, piano teaching master classes, piano performance exchange activities, piano music performance salons, etc. held by some schools fully reflect the use of multiple platforms to investigate the professional level of students, and thus to a large extent It improves students' musical expressiveness.

\section{Conclusion}

In the piano performance teaching in colleges and universities, for the two-way subject of teaching, teachers and students, it is necessary to have a deep understanding of the concept of "performance". The so-called "performance" is actually a corresponding vocabulary, that is, the combination of performance and playing. Among them, playing mainly points to the technical level, while performance mainly points to the understanding and interpretation of the work. As an inseparable whole, the two reflect the value of piano performance in the interaction. The diversification of current piano music creation styles and the diversification of piano performance skills not only reflect the high development of piano art, but also put forward higher requirements for performance teaching. No matter what style of music is played, it needs to show its intrinsic value through musical performance. Therefore, in piano performance teaching, on the one hand, we should pay attention to the teaching of performance skills, and on the other hand, we should cultivate students' practical ability from the perspective of performance. In the process of realizing these two aspects, in addition to reviewing their own teaching methods, teachers also need to start from the actual learning of students, discover the problems of students in time, and provide timely guidance. The famous German pianist Gissegin in the 20th century said that "only by trying to embody the expressive intentions of the composer, can a performer be able to deal with his work in an artistic way". This sentence actually puts forward the requirement of focusing on cultivating students' musical expressiveness for piano performance teaching, and it is also the key point for piano teachers and students to grasp in the teaching process.

\section{References}

[1] Fan Qiaojie. Balance between piano performance and teaching. Sichuan Drama. 2021; (6).

[2] Yan Xiaonan, Yin Aiqing. Discussion on the professional development of piano teachers from the perspective of teacher professional development. Journal of Northeast Normal University (Philosophy and Social Sciences Edition). 2020; (9).

[3] Xian Jinsong, Fei Zhen. On the significance and technical training of the three elements of sound in piano performance and teaching. Journal of Xinghai Conservatory of Music. 2020; (4). 